\title{
HYDATID CYST OF ORBIT WITH PROPTOSIS
}

\author{
Adhikari R C*, Sayami G*, Sharma A K \\ Lee M C ${ }^{\star}$, Dali $\mathbf{S}^{*}$, Shrestha H G $^{*}$
}

\section{ABSTRACT}

Hydatid cyst of orbit is a rare cause of proptosis, even in endemic regions. So far, Hydatid cyst of the orbit, has not been reported from Nepal. We report a 7-year-old boy, who presented with initially painful, later painless axial proptosis of the right eye without ocular movements and perception of light. As the case was clinically diagnosed as retinoblastoma or rhabdomyosarcoma, the exenteration was carried out.The retroorbital cyst containing gel-like fluid was histopathologically examined and the diagnosis of hydatid cyst was confirmed. Although rare, orbital hydatid cyst should be considered as one of the differential diagnoses of unilateral severe proptosis.

Key Words: Orbit, Hydatid cyst, Proptosis.

\section{INTRODUCTION}

Hydatid cyst is caused by cystic larval (metacestode) stages of Echinococcus granulosus; which was first described by Goeze in $1782 .{ }^{1}$ E. granulosus is a cestode and worldwide in distribution. However, Mediterraneans, Middle East and South Asian Countries, Latin America, and China are major areas of human infections. The annual incidence rates of hydatidosis in man per 100,000 population were 1.2 in Iran, ${ }^{2} 0.4$ in Wales, ${ }^{3}$ 50 in China, Algeria, and Argentina. ${ }^{4}$

Man harbours the larval form and is infected due to intimate handling of infected dogs and by taking uncooked vegetables contaminated with infected canine feces. As the embryos bore the intestinal wall and reach the portal circulation, liver becomes the commonest site $(50 \%$ to $70 \%)$ for hydatid cyst. Some of the embryos may pass through the hepatic capillaries and enter the pulmonary capillaries and enter the systemic circulation to lodge in the various sites. So, lung is the second most frequent site of hydatid cyst. The other reported possible sites are urinary tract, ${ }^{5}$ heart, ${ }^{6}$ adrenal gland,${ }^{7}$ spleen, ${ }^{8}$ mediastinum, ${ }^{9}$ central nervous system, ${ }^{10}$ spine ${ }^{11}$ and other bones, ${ }^{12}$ soft tissues, ${ }^{13,14,15}$ kidney, ${ }^{16,17}$ peritoneum, ${ }^{17}$ retroperitoneal space ${ }^{16}$ etc.

Orbital hydatid cyst is very uncommon and has been reported to be less than $1 \%$ of all hydatid diseases. ${ }^{18}$ The main symptom is proptosis. ${ }^{19}$ Hydatid cyst of the orbit is a very rare cause of proptosis. To our knowledge, this is the first case of orbital hydatid cyst in Nepal.

\section{CASE REPORT}

The patient was a 7-year-old boy, who presented with initially painful, later painless progressive protrusion of the right eyeball, loss of vision, redness and watering of the right eye for 3 months. Personal and past histories were not significant. No family member or relatives had a history of unexplained blindness or eye tumors. Systemic examination findings were unremarkable.

\footnotetext{
* Tribhuvan University Teaching Hospital, Maharajgunj, Kathmandu, Nepal. Address for correspondence : $\quad$ Dr. Ram Chandra Adhikari Department of Pathology Tribhuvan University Teaching Hospital, Maharajgunj, Kathmandu, Nepal Email: rcadhikari@hotmail.com
} 
On examination, the left eye was apparently normal. The extraocular movements on the right eye were totally restricted in all directions. There was no perception of light. Proptosis was axial and significant; eyelids were retracted. Conjunctiva was congested and chemosed. Cornea was totally sloughed out. Anterior chamber could not be assessed. Routine blood examination revealed $\mathrm{Hb} 11.7 \mathrm{gm} / \mathrm{dl}, \mathrm{RBC} 50,20,000 / \mu \mathrm{l}, \mathrm{WBC}$ $12,700 / \mu$ l with $73 \%$ neutrophils, $20 \%$ lymphocytes, $3 \%$ monocytes, $3 \%$ eosinophils, and $1 \%$ basophil, and platelets $3,68,000 / \mu 1$. Blood sugar (random) level was $6.7 \mathrm{mmol} / \mathrm{L}$ and LDH was $300 \mathrm{u} / \mathrm{L}$. Chest $\mathrm{x}$-ray did not reveal any cystic structures in the lung and ultrasonography of abdominal viscera was normal. No cysts in the liver were detected. CT scan of the brain was normal. CT scan of the orbit was not done. The case was clinically suspected as rhabdomyosarcoma or retinoblastoma. The exenteration was carried out because of severe proptosis, absence of light perception, and clinical diagnosis of malignancy. During exenteration, a retro-orbital cyst of a size $20 \mathrm{~mm} \times 8 \mathrm{~mm}$ was found. It was accidentally ruptured and yielded gel-like fluid. The cyst wall appeared as a membranous, tough, opaque structure.

\section{Histopathological findings}

Gross features: The exenteration specimen consisted of eyeball with portions of eyelids and multiple whitish opaque membrane like structures. The eyeball measured $5 \mathrm{~cm} \times 3.5 \mathrm{~cm} \times 3 \mathrm{~cm}$. Membranous structures altogether measured $1.0 \mathrm{~cm} \times 0.6 \mathrm{~cm}$. The cornea appeared necrosed. Other structures of the eyeball and optic nerve were grossly unremarkable.

Microscopic features: The sections from membranous structures showed eosinophilic laminated membrance, typical of hydatid cyst (Fig. 1). The granular germinal layer and free brood capsules (Fig. 2) were also present. Scolex or daughter cysts were not found. The eyeball showed chronic inflammatory cell infiltration involving the sclera and uvea. Thus, the final diagnosis of primary orbital hydatid cyst without involvement of any other sites was made.

Fig. 1: Eosinophilic laminated membrane, typical of hydatid cyst. Magnification x 40. Hematoxylin \& Eosin stain.

\section{Fig. 2: The granular germinal layer and free brood capsules.} Magnification x 40. Hematoxylin \& Eosin stain.

\section{DISCUSSION}

Echinococcosis occurs in human after contamination by infected dust of dog. It may localize in any parts of the body, but the liver and lung are the most frequent sites. The orbit is an unusual site for echinococcosis. ${ }^{18}$

In a study of Gomez Morales A et al. ${ }^{21}$ the average age of patients with orbital hydatid cysts was 16 years with a range of 2-57 years. Our patient was 7 years old. The clinical feature ${ }^{20,21}$ of orbital hydatid cyst are proptosis, diminished visual acuity, inflammatory signs and ocular palsy. Our case showed proptosis, loss of vision, inflammatory signs, and impaired ocular movements. These features may be present in other ocular and orbital diseases ${ }^{20}$ such as retinoblastoma, rhabdomyosarcoma, inflammatory pseudotumors, capillary hemangioma, chloroma, glioma, lymphangioma etc. So the clinical diagnosis of orbital hydatid cyst is often difficult. Our case was also clinically diagnosed as retionoblastoma or rhabdomyosarcoma and incidentally diagnosed as hydatid cyst after histopathological examination. Other investigations including ultrasound, ${ }^{22} \mathrm{CT}$ scan, ${ }^{22,23}$ and serology may be helpful. Serological investigations ${ }^{19}$ include intradermal test, indirect hemagglutination, counter-immunoelectrophoresis etc. In our case, serological tests were not done. Ultrasound could not be performed because the cornea was melted, anterior chamber was obliterated and the eyeball was grossly disfigured. The diagnosis can be confirmed by histopathological examination of the cyst. The cyst wall of metacestodes consists of three layers, inner, middle, and external. The middle or laminated layer is unique to the genus Echinococcus. ${ }^{24}$ The final diagnosis of our case was made postoperatively by detecting the laminated layer on histopathological examination.

The main treatment modality for orbital hydatid cyst is surgery. ${ }^{19}$ For inoperable cases chemotherapy with 
mebendazole seems promising. ${ }^{25}$ In our case, exenteration was performed as the case was clinically diagnosed as retinoblastoma or rhabdomyosarcoma and the patient was discharged with improvement.

\section{CONCLUSION}

This case report emphasizes that orbital hydatid cyst should be considered in the differential diagnosis in patients with unilateral severe proptosis with gross disfigurement of the globe especially in endemic regions for echinococcosis.

\section{REFERENCES}

1. Chatterjee KD. Parasitology (Protozoology and helminthology) in relation to clinical medicine. Sree Saraswaty Press Ltd., 1980, p.121-127.

2. Taratuto LA, Venturiello MS. Echinococcosis. Brain Pathology 1997; 7:673-679.

3. Palmer SR, Biffin AHB. The changing incidence of hydatid disease in England and Wales. Epidemiology and Infection. 1987; 99: 693-700.

4. Craig PS, Rogan MT, Allan CJ. Hydatidosis and cysticercosis larval cestodes. In: Gillesrie SH, Hawkey PM eds. Medical Parasitology. 1st ed. Oxford: IRL Press at Oxford University. 1995: 209-239.

5. Ozbey I, Aksoy Y, Bicgi O, Polat O. Hydatid disease of the urinary tract: review of the management of 9 cases. Int Urol Nephrol 2001; 33: 329-334.

6. Thameur H, Abdelmoula S, Chenik S, et al. Cardiopericardial hydatid cysts. World J Surg 2001; 25: 58-67.

7. el Idrissi Dafali A, Dahami Z, Zerouali NO. Hydatid cyst of the adernal gland. A case report. Ann Urol 2002; 36: 99-103.

8. Ozdogan M, Baykal A, Keskek M, Yorgancy K, Hamaloglu E, Sayak I. Hydatid cyst of the spleen: treatment options. Int Surg 2001; 86: 122-126.

9. Kabiri el H, al Aziz S, el Maslout A, Benosman A. Hydatid cyst: an unusual disease of the mediastinum. Acta Chir Belg 2001; 101: 283-286.

10. Turgut M. Intracranial hydatidosis in Turkey: its clinical presentation, diagnostic studies, surgical management, and outcome. A review of 276 cases. Neurosurg Rev 2001; 24: 200-208.

11. Pamir MN, Ozduman K, Elmaci I. Spinal hydatid disease. Spinal Cord 2002; 40: 153-60.

12. Martinez AA, Herrera A, Cuenca J, Herrerol L. Hydatidosis of the pelvis and hip. Int Orthop 2001; 25: 302-304.

13. Essadki O, el Hajjam M, Kadiri R. Hydatid cyst of soft tissues. Radiological Aspects. Ann Radiol 1996; 39: 135-141.

14. Karapinar K, Altinok D, Cetingok U, Duzgun C. Primary posterior chest wall echinococcosis. Int Surg 1999; 84: 89-90.

15. Lamine A, Fikry T, Zryouil B. Primary hydatidosis of the peripheral muscles. 7 case reports. Acta Orthop Belg 1993; 59:184-188.

16. Proualidis J, Tzardinoglou K, Sgouradis L, Katsohis C, Aletras H. Uncommon sites of hydatid disease. World J Surg 1998; 22:17-22.

17. Khiari A, Fabre JM, Mzali R, Domergue J, Beyrouti MI. Unusual locations of hydatid cysts. Ann Gastroenterol Hepatol 1995; 31: 295-305.

18. Ergun R, Okten AI, Yuksel M, et al. Orbital hydatid cysts: report of four cases. Neurosurg Rev 1997; 20: 33-37.

19. Xiao A, Xueyi C. Hydatid cysts of the orbit in Xinjiang: a review of 18 cases. Orbit 1999;18: 151-155.

20. Belmekki M, el Bakkali M, Abdellah H, Benchrifa F, Berraho A. Epidemiology of orbital processes in children. 54 cases. $J$ Fr Ophtalmol 1999; 22: 394-398.

21. Gomez Morales A, Croxatto JO, Crovetto L, Ebner R. Hydatid cysts of the orbit. A review of 35 cases. Ophthalmology 1988; 95: 1027-1032.

22. Mahesh L, Biswas J, Subramanian N. Role of ultrasound and CT-scan in diagnosis of hydatid cyst of the orbit. Orbit 2000; 19: 179- 188 .

23. Khalili AH. CT Values in orbital hydatid cyst. Comput Radiol 1987;11: 193-197.

24. Taherkhani H, Rogan MT. General characterization of laminated layer of Echinococcus granulosus. Irn J Med Sci 2000; 25:95104.

25. Staindl O, Krenkel C. Echinococcosis of the orbit. HNO 1985;33:404-408. 